\title{
Alclofenac and D-penicillamine
}

\section{Comparative trial in rheumatoid arthritis}

\author{
H. BERRY $Y^{1}$, L. FERNANDES ${ }^{1}$, A. W. FORD-HUTCHINSON ${ }^{2}$, S. J. W. EVANS, ${ }^{3}$ \\ AND E. B. D. HAMILTON ${ }^{1}$
}

From the Departments of Rheumatology ${ }^{1}$ and Chemical Pathology, ${ }^{3}$ King's College Hospital; and Department of Statistics, London Hospital ${ }^{2}$

SUMMARY Forty-six patients with rheumatoid arthritis, 22 receiving D-penicillamine and 24 alclofenac, took part in a 6-month single-blind external observer trial to compare the efficacy and toxicity of these drugs in the treatment of severe rheumatoid arthritis. Both drugs were active and similar in their efficacy at 6 months as judged by clinical and laboratory measurements. Penicillamine was active therapeutically by 3 months, one month before alclofenac. 9 patients, 8 on alclofenac and one on D-penicillamine, had to stop treatment because of lack of effect or toxic effects. Skin rashes within the first week of treatment were a major problem with alclofenac and led to 6 withdrawals.

Alclofenac has been shown to have useful analgesic anti-inflammatory properties in the treatment of rheumatoid arthritis (Aylward, 1973). Further studies have suggested greater efficacy than aspirin (Aylward et al., 1974) and indomethacin (Aylward et al., 1975). It seemed appropriate to evaluate this drug in the management of severe rheumatoid arthritis.

D-penicillamine, originally discovered by Abraham et al. (1942) and first used clinically by Walshe (1956) in the treatment of Wilson's disease, has been used increasingly in the treatment of severe rheumatoid arthritis. It was first validated by the multicentre study of Andrews et al. (1973). Subsequently its place has been established by the finding of comparable efficacy with gold (Huskisson et al., 1974) and azathioprine (Berry et al., 1976). In view of the now established value of penicillamine, it was used as the comparative drug in this study.

\section{Methods}

A single-blind external observer trial was performed at King's College Hospital. The trial supervisor (H.B.), who was aware of the treatment allocation, was responsible for routine management, checking blood tests and urine analysis results, and listing

Accepted for publication September 10, 1977

Correspondence to Dr H. Berry, . Department of Rheumatology, King's College Hospital, Denmark Hill, London SE5. unwanted side effects described by the patients. A 'blind' observer (L.F.) assessed the severity of the disease.

\section{PATIENT SELECTION}

Outpatients attending the department of rheumatology were admitted to the trial if they were over 18 years of age and had definite or classical rheumatoid arthritis, including either positive rheumatoid factor (latex titre $1 / 80$ or more) or erosive changes on $x$-rays of the hands, feet or both. The disease had to be severe enough for the clinician to conventionally consider the use of gold. If the patients were receiving steroid therapy, the dosage had to have been stable for the preceding 6 months. Criteria for exclusion were (a) treatment in the preceding 6 months with gold, azathioprine, or at any time with alclofenac or D-penicillamine; (b) abnormally low white cell count or platelet count at any time; (c) evidence of renal impairment (raised blood urea or serum creatinine); (d) risk of pregnancy. Informed consent was obtained from all patients at the beginning of the trial.

\section{DRUGS}

Alclofenac $1 \mathrm{~g}$ three times daily was compared with penicillamine $750 \mathrm{mg}$ daily reached by $250 \mathrm{mg}$ increments every 4 weeks. Patients were randomly allocated to either treatment and were only stratified for current corticosteroid administration. In addition to the trial drugs, patients continued to receive a 
regular dose of the anti-inflammatory/analgesic drug they had been receiving before the study; this had to have been stable for the preceding month. Only paracetamol was allowed in addition. All medication was issued through normal outpatient prescribing channels.

\section{ASSESSMENTS}

The following measurements were made at the beginning of the trial and monthly for 6 months.

(a) Pain using the 20-point visual analogue scale. (b) Pain using the 4-point scale $(1=$ nil, 2=mild, 3=moderate, $4=$ severe. (c) Articular index (Ritchie). (d) Grip strength (bag inflated to $30 \mathrm{~mm}$ repeated three times, taking the sum of the last 2 readings for each hand). (e) Ring size using the Geigy ring size measuring device. (f) Early morning stiffness measured in minutes.

\section{LABORATORY MEASUREMENTS}

All laboratory measurements were made before treatment with either penicillamine or alclofenac and at monthly intervals thereafter. The erythrocyte sedimentation rate was measured by the method of Westergren. Total and differential white cell and platelet counts were performed by standard methods. IgM, IgG, and IgA were determined by fluoronephelometry using the Technicon AIP system, and IgE determined by radioimmunoassay (Pharmacia). Fibrinogen, $\alpha_{1}$-acid glycoprotein, $\alpha_{1}$-antitrypsin, $\alpha_{2}$-macroglobulin, and albumin were measured by radial immunodiffusion methods (Fahey and McKelvey, 1965) using commercial reagents (Behring diagnostic reagents, Hoechst Pharmaceuticals, Hounslow, England). Urine was tested for protein and blood on each visit.

\section{PROCEDURE}

Patients were assessed monthly during the study. Treatment was stopped if the white blood cell count or platelet count fell below the lower limit of normal (white cells $4 \times 10^{9} / 1\left(4000 / \mathrm{mm}^{3}\right)$; platelets $150 \times 10^{9} / 1$ $\left.\left(150000 / \mathrm{mm}^{3}\right)\right)$. On recovery the drug was gradually reintroduced. If the problem recurred, then the patient was withdrawn from the trial, continuation of treatment representing an unreasonable risk to the patient.

\section{Results}

Forty-six patients were admitted to the trial; 24 received alclofenac ( 18 female) and 22 penicillamine (16 female). 37 completed 26 weeks (16 on alclofenac and 21 on penicillamine: Table 1$) .3$ ( 2 on alclofenac and 1 on penicillamine) were withdrawn because of lack of effect and 6, all on alclofenac, were withdrawn during the first week of the trial because of skin rash. Restarting the drug produced a skin rash again. The mean age in the penicillamine group was 56.5 years and 55.9 years in the alclofenac group and? the mean duration of disease was 9.4 years and 7. years respectively.

Table 1 Patient selection

\begin{tabular}{|c|c|c|}
\hline & Alclofenac & Penicillamine \\
\hline Number of patients & 24 (18 females) & 22 (16 females) \\
\hline Mean age (years) & $55 \cdot 9$ & $56 \cdot 5$ \\
\hline $\begin{array}{l}\text { Mean duration of disease } \\
\text { (years) }\end{array}$ & $7 \cdot 7$ & $9 \cdot 4$ \\
\hline
\end{tabular}

Table 2 Clinical results (I) (mean values)

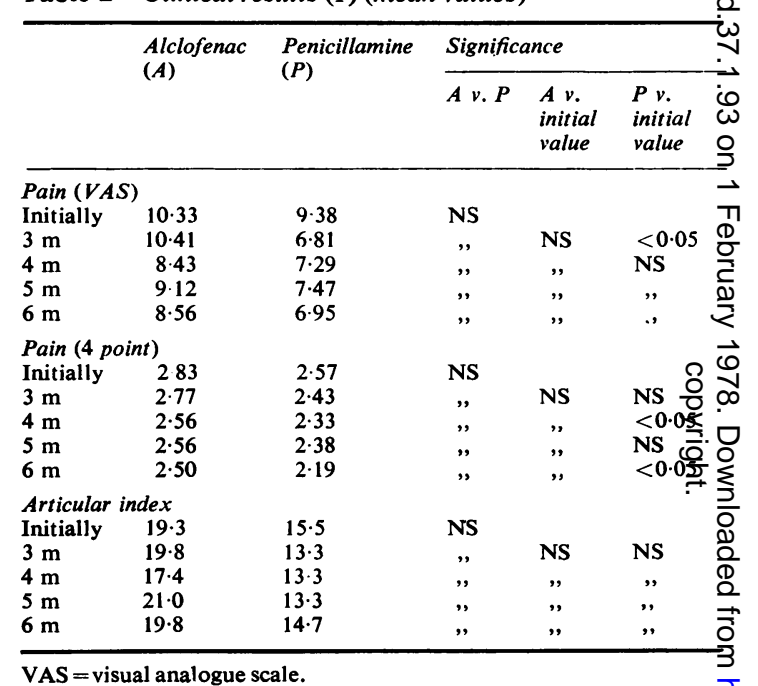

VAS $=$ visual analogue scale.

Table 3 Clinical results (2) (mean values)

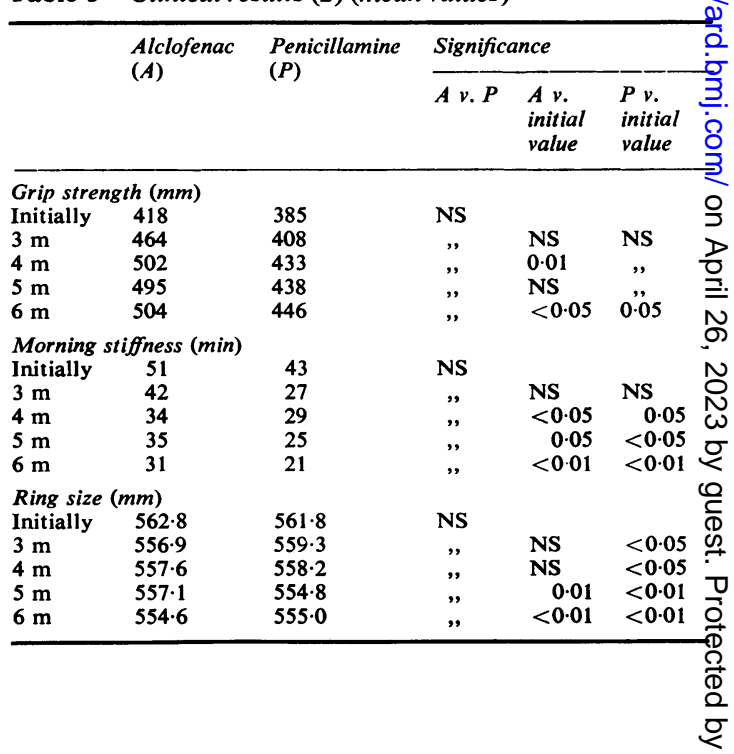


The clinical and laboratory results are shown in Tables 2-5. By 3 months while there was statistically significant relief of pain (visual analogue scale), reduction in ring size, reduction in rheumatoid factor titre, ESR, fibrinogen, and IgM levels in those receiving penicillamine compared with the beginning of the trial, no such changes were seen in the patients treated with alclofenac. The improvement in haemoglobin and the fall in ESR reached significance in between-group analysis at this time. By 4 months patients treated with alclofenac showed significant improvement in grip strength, early morning stiffness, IgG and IgM levels, and improvement in haemoglobin levels compared with the

Table 4 Laboratory results (1) (mean values)

\begin{tabular}{|c|c|c|c|c|c|}
\hline & \multirow{2}{*}{$\begin{array}{l}\text { Alclofenac } \\
(A)\end{array}$} & \multirow{2}{*}{$\begin{array}{l}\text { Penicillamine } \\
(P)\end{array}$} & \multicolumn{3}{|c|}{ Significance } \\
\hline & & & $A$ v. $P$ & $\begin{array}{l}\text { A v. } \\
\text { initial } \\
\text { value }\end{array}$ & $\begin{array}{l}P v . \\
\text { initial } \\
\text { value }\end{array}$ \\
\hline \multicolumn{6}{|l|}{$H b(g)$} \\
\hline Initialiy & $12 \cdot 06$ & $11 \cdot 71$ & & & \\
\hline $3 \mathrm{~m}$ & $12 \cdot 08$ & 12.69 & $<0.05$ & NS & $<0.01$ \\
\hline $4 \mathrm{~m}$ & $12 \cdot 56$ & $12 \cdot 60$ & NS & $<0.05$ & $<0.01$ \\
\hline $5 \mathrm{~m}$ & $12 \cdot 86$ & $12 \cdot 65$ & , & $<0.01$ & $<0.01$ \\
\hline $6 \mathrm{~m}$ & 13.07 & $12 \cdot 81$ & ", & $<0.01$ & $<0.01$ \\
\hline \multicolumn{6}{|c|}{ Rhcumatoid factor (d:lutions) } \\
\hline Initially & 3.56 & $3 \cdot 62$ & & & \\
\hline $3 \mathrm{~m}$ & $3 \cdot 17$ & 2.09 & NS & NS & $<0.05$ \\
\hline $4 \mathrm{~m}$ & $2 \cdot 75$ & $2 \cdot 90$ & , & , & NS \\
\hline $5 \mathrm{~m}$ & $3 \cdot 31$ & $2 \cdot 71$ & ", & $"$ & , \\
\hline $6 \mathrm{~m}$ & $2 \cdot 81$ & $2 \cdot 71$ & ", & $"$, & $"$, \\
\hline \multicolumn{6}{|c|}{$E S R(\mathrm{~mm})$} \\
\hline Initially & $58 \cdot 3$ & 56.6 & & & \\
\hline $3 \mathrm{~m}$ & 52.6 & $39 \cdot 2$ & 0.05 & NS & $<0.01$ \\
\hline $4 \mathrm{~m}$ & 39.9 & $34 \cdot 1$ & NS & $<0.01$ & $<0.01$ \\
\hline $5 \mathrm{~m}$ & $38 \cdot 2$ & $36 \cdot 1$ & , & $<0.01$ & $<0.01$ \\
\hline $6 \mathrm{~m}$ & $36 \cdot 1$ & 32.0 & ", & $<0.01$ & $<0.01$ \\
\hline
\end{tabular}

Table 5 Laboratory results (2) (mean values)

\begin{tabular}{|c|c|c|c|c|c|}
\hline & \multirow{2}{*}{$\begin{array}{l}\text { Alclofenac } \\
\text { (A) }\end{array}$} & \multirow{2}{*}{$\begin{array}{l}\text { Penicillamine } \\
(P)\end{array}$} & \multicolumn{3}{|c|}{ Significance } \\
\hline & & & $A$ v. $P$ & $\begin{array}{l}\text { A v. } \\
\text { initial } \\
\text { value }\end{array}$ & $\begin{array}{l}P v . \\
\text { initial } \\
\text { value }\end{array}$ \\
\hline \multicolumn{6}{|c|}{ Fibrinogen $(g / l)$} \\
\hline Initial:y & $5 \cdot 43$ & $5 \cdot 45$ & & & \\
\hline $3 \mathrm{~m}$ & $5 \cdot 18$ & 5.09 & NS & NS & $<0.05$ \\
\hline $4 \mathrm{~m}$ & $5 \cdot 32$ & $5 \cdot 29$ & ", & ", & $<0.05$ \\
\hline $5 \mathrm{~m}$ & $5 \cdot 25$ & $4 \cdot 86$ & ", & & $<0.01$ \\
\hline $6 \mathrm{~m}$ & $4 \cdot 97$ & $4 \cdot 82$ & $"$ & $<0.05$ & $<0.01$ \\
\hline Ini ially & $2 \cdot 89$ & $2 \cdot 06$ & & & \\
\hline $3 \mathrm{~m}$ & $2 \cdot 59$ & 1.48 & NS & NS & $<0.01$ \\
\hline $4 \mathrm{~m}$ & 2.46 & 1.52 & , & $<0.05$ & $<0.01$ \\
\hline $5 \mathrm{~m}$ & $2 \cdot 46$ & 1.08 & ", & $<0.05$ & $<0.01$ \\
\hline $6 \mathrm{~m}$ & $2 \cdot 28$ & $1 \cdot 50$ & $"$ & NS & $<0.01$ \\
\hline \multicolumn{6}{|l|}{$I g G(g / l)$} \\
\hline Initially & $15 \cdot 2$ & $15 \cdot 0$ & & & \\
\hline $3 \mathrm{~m}$ & $14 \cdot 5$ & $15 \cdot 9$ & NS & NS & NS \\
\hline $4 \mathrm{~m}$ & $13 \cdot 2$ & $14 \cdot 5$ & " & $<0.05$ & "̈n? \\
\hline $5 \mathrm{~m}$ & $13 \cdot 1$ & $13 \cdot 0$ & ", & $<0.01$ & $<0.01$ \\
\hline $6 \mathrm{~m}$ & $12 \cdot 0$ & $14 \cdot 0$ & ", & $<0.01$ & NS \\
\hline
\end{tabular}

beginning of the trial and comparable with the results seen with penicillamine. Figs. 1 and 2 indicate improvement in haemoglobin level and fall in ESR during the course of the trial. No significant changes were observed in the levels of $\alpha_{1}$-acid glycoprotein, $\alpha_{1}$-antitrypsin, albumin, $\alpha_{2}$-macroglobulin, IgA, or IgE after treatment with either drug.

\section{WITHDRAWALS}

Eight patients were withdrawn from alclofenac therapy and one from penicillamine therapy. Skin rashes led to 6 of the alclofenac withdrawals. The other withdrawals in the trial were due to lack of effect (Table 6).

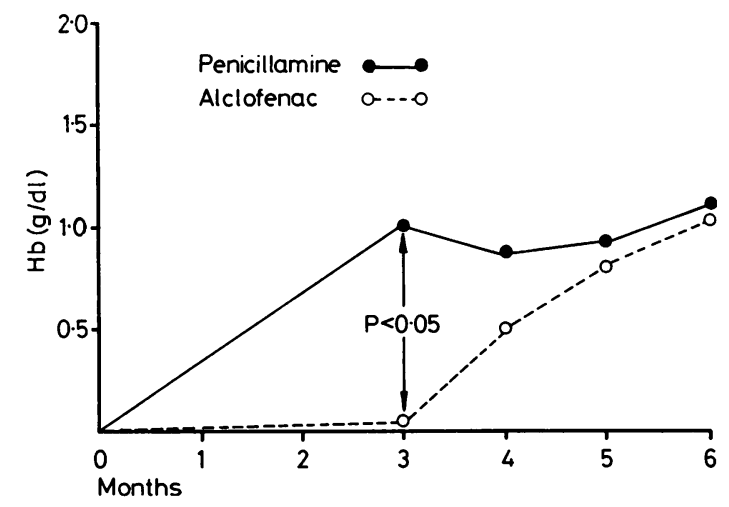

Fig. 1 Improvement in haemoglobin concentrations.

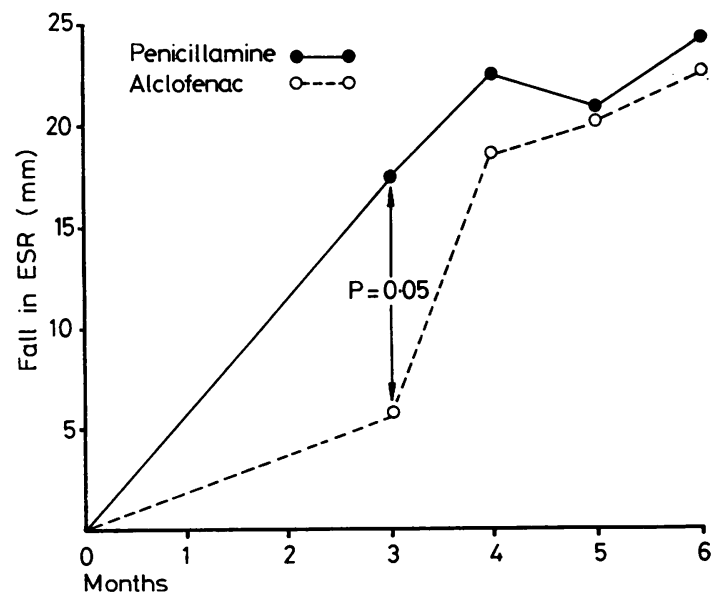

Fig. 2 Fall in ESR. 
Table 6 Withdrawals from trial

\begin{tabular}{lll}
\hline & Alclofenac & Penicillamine \\
\hline Total no. & 8 & 1 \\
Lack of effect (n) & 2 & 1 \\
Skin rash (n) & 6 & 0 \\
\hline
\end{tabular}

Table 7 Unwanted side effects

\begin{tabular}{lll}
\hline & Alclofenac & Penicillamine \\
\hline Total no. & 12 & 12 \\
Taste loss & 0 & 5 \\
Indigestion & 2 & 2 \\
Nausea & 0 & 1 \\
Diarrhoea & 0 & 1 \\
Skin rash & 8 & 0 \\
Thrombocytopenia & 0 & 2 \\
Dizziness & 0 & 1 \\
Depression & 1 & 0 \\
Skin irritation & 1 & 0 \\
\hline
\end{tabular}

\section{SIDE EFFECTS}

Twelve side effects occurred in those patients receiving penicillamine and 12 with alclofenac. Of the penicillamine side effects, 5 were taste loss, 1 nausea, 2 indigestion, 1 diarrhoea, 1 dizziness, and 2 thrombocytopenia. 12 side effects also occurred in patients taking alclofenac. In addition to the 6 early skin rashes which led to withdrawal, there were 2 additional skin rashes that did not necessitate withdrawal because reintroduction of the drug did not reprovoke the skin rash, 1 case of skin irritation, 1 depression, and 2 indigestion (Table 7).

\section{Discussion}

It is generally accepted that there is a difference between the clinical antirheumatic effects of nonsteroidal anti-inflammatory drugs, such as aspirin and indomethacin, to that induced by treatment with penicillamine, gold, and azathioprine. The latter group produce a delayed response compared with the former and their use is restricted to more severe cases of the disease due, at least in part, to their toxicity. The present trial was designed to detect the delayed type of response because any clinical improvement which was detected had to be superimposed on that produced by existing therapy. Penicillamine, which was used as the reference drug, produced the expected result. By 3 months it had caused a statistically significant improvement in pain relief, ring size, fall in ESR, fibrinogen, IgM, and rheumatoid factor, and increased haemoglobin concentration compared with the beginning of the study. The second drug, alclofenac, had been evaluated by other workers primarily with respect to its activity in comparison with aspirin and indomethacin. There was no evidence that resembled the penicillamine-gold-azathioprine group in its effects (Aylward, 1973; Aylward et al., 1974․ 1975). The present results, however, showed that by 4 months patients treated with alclofenac showe significant improvement in grip strength, early morning stiffness, IgM, IgG, and haemoglobity concentrations and fall in ESR compared with the beginning of the trial.

This study confirmed the problem of skin ras $\mathbb{R}^{2}$ related to alclofenac capsule therapy. The severe rash seemed to be an early hazard, being confined t $\vec{\oplus}$ the first week of the study. It disappeared on stopping the drug but did not recur when the patient was rechallenged. Later rashes experienced in this stude were minor and on rechallenging did not recuro This was the only major problem experienced with alclofenac and is in marked contrast to the side effects seen with penicillamine which are major an\& potentially life-threatening hazards. These mostlo occur at or beyond 9 months from the beginning of treatment and were not encountered in this 6-month study except for 2 cases of thrombocytopenia. One case has been reported of skin vasculitis which wa fatal while alclofenac was being taken, but this coule have been a side effect of disease rather than therapy (Billings et al., 1974). So far the only long-term stoddo of alclofenac failed to show serious toxicity (Aylward et al., 1974) but more long-term work is neefe before being certain that alclofenac is free of this risk. This study did not answer this question.

It must be concluded that alcofenac, as well as possessing anti-inflammatory activity similar t $\Theta$ aspirin, also shows a penicillamine-type response an $\vec{\Phi}$ can thus be considered as an alternative treatment $t \overrightarrow{\widehat{\theta}}$ gold, penicillamine, and azathioprine. Whether should be used in this manner must depend on the results of trials conducted over a longer period, o\& clinical experience, and consideration of the side effects of the two drugs.

We acknowledge support from Merck, Sharp an£ Dohme, Ltd, who provided D-penicillamine and supported laboratory tests. We thank Dista Pharma ceuticals for financial support for laboratory tests and Mrs M. E. Henderson for unstinting help in the organisation of this study, without which this triaf would not have been possible.

\section{References}

Abraham, E. P., Chain, E., Baker, W., and Robinson, R (1942). Penicillamine, characteristic degradation produ of penicillin. Nature, 151, 107.

Andrews, F. M., Freeman, A. H., Golding, J. R., Day, A. T Hill, A. G. S., Camp, A. V., Lewis-Faning, E., and Lylę W. H. (1973). Controlled trial of D(-)penicillamine in severe rheumatoid arthritis. Lancet, 1, 275-280. 
Aylward, M. (1973). Alclofenac in rheumatoid arthritis: an evaluation of its anti-inflammatory and analgesic effects. British Journal of Clinical Practice, 27, 255-260.

Aylward, M., Parker, R. J., and Maddock, J. (1974). Studies on a 4-allylocy-3 chlorophenylacetic acid (alclofenac). A double blind comparison of alclofenac and aspirin in rheumatoid arthritis and effects of therapy on serum immunoglobulins and rheumatoid factor. Annals of the Rheumatic Diseases, 33, 268-272.

Aylward, M., Parker, R. J., Holly, F., Maddock, J., and Davies, D. B. S. (1975). Non-steroidal antirheumatic drugs in the treatment of rheumatoid arthritis: a long-term study of indomethacin and alclofenac. British Medical Journal, 2, 7-9.

Berry, H., Liyanage, S., Durance, R. A., Barnes, C. G., Berger, L. A., and Evans, S. (1976). Azathioprine and penicillamine in treatment of rheumatoid arthritis: a controlled trial. British Medical Journal, 1, 1052-1054.

Billings, R. A., Burry, H. C., Emslie, F. S., ano Kerr, G. D. (1974). Vasculitis with alclofenac therapy. British Medical Journal, 4, 263-265.

Fahey, J. L., and McKelvey, E. M. (1965). Quantitative determinations of serum immunoglobulins in antibodyagarplates. Journal of Immunology, 94, 84-90.

Huskisson, E. C., Gibson, T. J., Balme, H. W., Berry, H., Burry, H. C., Grahame, R., Hart, F. D., Henderson, D. R. F., and Wojtulewski, J. A. (1974). Trial comparing D-penicillamine and gold in rheumatoid arthritis. Preliminary report. Annals of the Rheumatic Diseases, 33, 532535.

Walshe, J. M. (1956). Wilson's disease. New oral therapy. Lancet, 1 , 25-26. 


\section{Correspondence}

\section{Rheumatism in retrospect}

Sir,

As World Rheumatism Year has now closed, it might be of value for the younger supporters, who have always been 'respectable', to learn of our pre-War problems.

When I passed my Membership in 1933, by luck first time, I suddenly realised that I could not have given a reasonable answer to a question on rheumatoid arthritis, although $I$ had at my fingertips details of every obstruse cerebral condition known. I therefore went to my chief, Professor Sir Francis Fraser, and told him I wished to make a part-time study of the rheumatic diseases. His reply was, 'My boy, I have been training you to be a respectable physician at Barts and you now decide to prostitute your soul by associating with every quack in the Universe'. My reply-'How then can Medicine improve?' He then helped me all he could. The only rheumatologist at that time with any senior degree was Will Copeman and even he was suspect for his interest and I certainly took a step down the ladder. Horder, the clinician of this century, was the one visionary when he founded the Empire Rheumatism Council, now the Arthritis and Rheumatism Council, in 1936, with Will Copeman as medical secretary and myself about the most junior member. A year later the Heberden Society was conceived by the staff of the Peto Place British Red Cross Society Rheumatology Clinic.

Gradually rheumatology became respectable, helped by the discovery of cortisone by an American rheumatologist,
Phil Hench. Now we have five Chairs and three major specialist research units and every scientist values its importance. But still, under the NHS, though it constitutes a third of the complaints to GPs, it is funded by only $4.5 \%$ of the budget.

Physical medicine and rehabilitation had the same difficult beginnings and again Horder sorted it out. The War made rehabilitation important but the Barons of Harley Street (led by Morton Smart and Robert Stanton Woods), the Emergency Medical Service (Frank Cooksey), and Service specialists (Frank Howitt), and other specialists, like Philippe Bauwens, world authority on medical electricity, but uninterested in other problems, were fighting like cats and dogs, till Horder gave a lunch party at Claridges in 1942 and figuratively bumped their heads together. The result was the British Association of Physical Medicine.

When will manipulative medicine be properly brought into the medical curriculum and receive the cloak of respeztability? As Horder once wrote, 'It takes a long time for the Princes of Medicine to take Cinderella to the dance', though today they do a little more readily let their eyes rove over the form.

GEORGE KERSLY
Royal National Hospital for Rheumatic Diseases,
Upper Borough Walls,
Bath BA1 IRL.

\section{Errata}

In the paper 'Alclofenac and D-penicillamine' by $\mathrm{H}$ Berry et al. (pp. 93-97, February issue), the sentence in the second paragraph of the Discussion, 'It disappeared on stopping the drug but did not recur when the patient was rechallenged' should read 'It disappeared on stopping the drug but recurred when the patient was rechallenged'.

The Second Prague Symposium on Rheumatology-Spinal Column, will be held from June 11th-14th, 1978, not July 12th-15th as published in the December issue of the Annals, 36, 591. 